\title{
Assessment of Heavy Metals Concentration in the Soil and Crops Grown around Dumpsites
}

\author{
Philomene Nyiramigisha ${ }^{1 *}$, Komariah $^{2}$, Sajidan $^{3}$ \\ ${ }^{1}$ Environmental Science Department, Postgraduate School of Sebelas Maret University, Surakarta 57126, Indonesia \\ ${ }^{2}$ Soil Science Department, Faculty of Agriculture, Sebelas Maret University., Surakarta 57126, Indonesia \\ ${ }^{3}$ Department of Biology Education, Faculty of Education and Teacher Training, Sebelas Maret University, Surakarta 57126, Indonesia
}

\section{Article History \\ Received: 26.02.2021 \\ Accepted: 29.03.2021 \\ Published: 16.04 .2021}

Journal homepage:

http://www.easpublisher.com

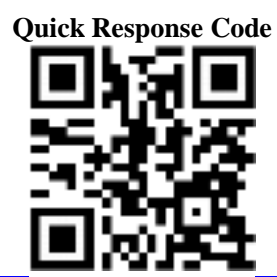

\begin{abstract}
This study assessed the levels of heavy metals ( $\mathrm{Mn}, \mathrm{Cr}, \mathrm{Pb}, \mathrm{Cd}$, and $\mathrm{Fe}$ ) in two dumpsites and control in Surakarta. Specific soil properties and the level of metals in dumpsite soil samples and crops were also considered. Standard techniques were employed in the appraisal and atomic absorption spectrophotometer (Buck Scientific model 210) for the metal concentration analysis. The level of each metal was detected low in the control site compared to the dumpsites which prove that there had been an anthropogenic contribution of heavy metal through the disposal of wastes contained or made of heavy metals. The crops in the two sites and control had $\mathrm{Cr}, \mathrm{Cd}$, and $\mathrm{Pb}$ occurring below the detection limit. All the concentrations of metals studied in soil and crops were found to be lower than the maximum permissible limit of heavy metal in soil and crops stated by the World Health Organization (WHO) which implies that the crops are presently safe for human consumption. The higher concentration of metals in the dumpsite and their crops more than the control site shows that there is gradual pollution of heavy metals in the crops and implies that there is a need to avoid consuming crops grown on these sites and discourage the use of the sites for any form farming activities.
\end{abstract} Keywords: Crops, Dumpsites, Heavy metals, Mojosongo, Soil pollution, Surakarta.

Copyright (C) 2021 The Author(s): This is an open-access article distributed under the terms of the Creative Commons Attribution 4.0 International License (CC BY-NC 4.0) which permits unrestricted use, distribution, and reproduction in any medium for non-commercial use provided the original author and source are credited.

\section{INTRODUCTION}

The disposal of wastes is a notable implication of modernization [1]. This has automatically resulted in massive environmental pollution, specifically in developing countries where important efforts towards developed waste management and disposal practices have not been made [2]. Similarly, with the rising influence in the more technologically developed countries, more municipal solid wastes and wastewaters are being produced and these needed treatment and proper disposal. According to Rachim [3], there is no doubt that a healthy environment has a high correlation with good human health.

Some disposed materials which contain heavy metals in open dumpsites are of concern and pose dangers to people in contact with the soil and plants of these sites in which they are disposed of [4]. According to Ugurlu [4], Surakarta, leachates from refuse dumpsites constitute a source of heavy metal pollution to both soil and aquatic environments. In some cases, wastes are dumped recklessly with no regard to the environmental implications, while in some dumpsites, wastes are burnt in the open and ashes abandoned at the sites [5]. The concentrations of heavy metals in the soil around waste dumpsites are influenced by types of wastes, topography, runoff, and level of scavenging [6]. Once heavy metals are deposited in the soil, they are not degraded and they persist in the environment for a long time causing serious environmental pollution [7].

There is an increasing concern about the likelihood of soil contamination resulting in the introduction of elements in food chains through uptake by plants and thereby affecting food safety [8]. They accumulate in soil and plants having a negative influence on physiological activities of plants such as photosynthesis, gaseous exchange, and nutrient absorption which result in plant growth reduction and dry matter accumulation [9]. Although the rate of metal uptake by plants could be influenced by factors such as metal species, plant species, etc. As it is in most cases, soils in municipal waste dumpsites commonly serve as fertile ground for the cultivation of a variety of crops, with little regard to the probable health hazards the heavy metal content of such soils may pose [10]. Most dumpsite soils in Indonesia are extensively used for cultivating varieties of crops without proper routine assessment of the associated health and ecological [2].

Normally, heavy metals occur naturally in the ecosystem with large differences in concentrations. 
Nowadays, pollution from the activities of humans has introduced some of these heavy metals into the ecosystem [11]. According to Postma et al. [12], the presence of heavy metals in the environment is of great ecological significance due to their toxicity at certain concentrations, translocation through food chains, and non-biodegradability which is responsible for their accumulation in the biosphere [13].

The use of dumpsites as farmlands is a common practice in urban and sub-urban centers across Asia because decayed and composted wastes enhance soil fertility [14]. These wastes often contain heavy metals in various forms and at different contamination levels. Human exposure to heavy metals occurs through three primary routes, i.e. inhalation, ingestion, and skin absorption. $\mathrm{Pb}$ is a particularly dangerous metal that has no biological role and negatively affects children in significant ways [15]. The environmental problem with heavy metals is that they are unaffected during the breakdown of organic waste and have toxic effects on living organisms when they exceed a certain concentration. The high concentration of heavy metals in soils is reflected by concentrations of metals in plants, water, animal, and human bodies.

Consequently, when pollutants from e-waste are washed into surrounding water bodies by rain or flood, there will be a change in the level of heavy metal concentration and nutrient concentration of the water bodies [14]. Heavy metal pollution of the environment, even at low levels, and their resulting long-term cumulative health effects are among the leading health concerns all over the world. For example, bioaccumulation of $\mathrm{Pb}$ in the human body interferes with the functioning of mitochondria, thereby impairing respiration, and also causes constipation, swelling of the brain, paralysis, and eventual death [16]. The situation is even more worrisome in the developing countries where research efforts towards monitoring the environment have not been given the desired attention by the stakeholders.

Heavy metals concentration in the environment cannot be attributed to geological factors alone, but human activities do modify considerably the mineral composition of soils, crops, and water [17]. The recent population and industrial growth have led to increased production of domestic, municipal, and industrial wastes, which are indiscriminately dumped in landfills and water bodies without treatment. Some heavy metals like $\mathrm{As}, \mathrm{Cd}, \mathrm{Hg}$, and $\mathrm{Pb}$ are particularly hazardous to plants, animals, and humans [18]. Municipal waste contains such heavy metals as $\mathrm{As}, \mathrm{Cd}, \mathrm{Co}, \mathrm{Cu}, \mathrm{Fe}, \mathrm{Hg}$, $\mathrm{Mn}, \mathrm{Pb}, \mathrm{Ni}$, and $\mathrm{Zn}$ which end up in the soil as the sink when they are leached out from the dumpsites. Soil is a vital resource for sustaining two human needs of quality food supply and quality environment. Plants grown on land polluted with municipal, domestic or industrial wastes can absorb heavy metals inform of mobile ions present in the soil solution through their roots or foliar absorption. These absorbed metals get bio-accumulated in the roots, stems, fruits, grains, and leaves of plants [4]. Heavy metals are described as those metals with a specific gravity higher or more than $5 \mathrm{~g} / \mathrm{cm}$. The most common heavy metals are copper, nickel, chromium, lead, cadmium mercury, and iron. Some heavy metals, such as iron and nickel are essential to the survival or all forms of life if they are low in concentrations [4]. However, heavy metals like lead, cadmium, and mercury are toxic to living organisms even in low concentrations, and they cause anomalies in the metabolic functions of the organism especially in greater quantities [14].

Exposure to heavy metals may cause blood, bone disorders, kidney damage, decreased mental capacity, and neurological damage [19]. Heavy metal toxicity can result in damaged or reduced mental and central nervous function, lower energy levels, and damage to blood composition, lungs, kidneys, liver, and other vital organs. One specific threat resulting from inadequate wastes disposal is the contamination by heavy metals that have a significant toxic potential for the environment (soil, water, and air), human beings, and the exposed biodiversity [20]. Population explosion and urbanization have increased the quantities and types of solid wastes produced [19].

Municipal solid waste usually contains paper, food waste, metal scraps, glass, ceramics, and ashes. The decomposition or oxidation process releases the heavy metal contained in these wastes to the soil of the waste dumpsite thereby contaminating the soil [21]. Investigation of heavy metals is very essential since slight changes in their concentration above the acceptable levels, whether due to natural or anthropogenic factors, can result in serious environmental and subsequent health problems [22]. The concentrations of heavy metals in the soil around waste dumps are influenced by types of wastes, topography, run-off and level of scavenging [23]. Solid waste dumped along roadsides is usually left over a long time to decompose naturally by microorganisms, eaten by animals, picked by scavengers or washed away by the floods into the larger creek and rivers thus affecting the surface water quality of contamination and are stored faster than they are excreted [11]. Indeed, many heavy metals are found to accumulate in fishes causing human contamination and related health issues. Heavy metals also affect agricultural products and their consumers [4].

Toxic heavy metals can also be taken directly by man and other animals through inhalation of dusty soil. Heavy metal pollutants such as copper [24] lead, and zinc Alloway and Davies, [18] from additives used in gasoline and lubricating oils are also deposited on highway soils and vegetation. Various studies have shown that dumpsite soils in these practices pose 
serious health and environmental concern due to the anthropogenic contamination of these waste soils with the intolerable level of chemical materials [25, 23].

The heavy metal content of soils is a critical measurement for assessing the risks of refuse dumpsites. However, only the chemical species/fractions of these heavy metals provide predictive insights on the bioavailability, mobility, and fate of the heavy metal contaminants $[21,26]$. Thus, there is a need to evaluate the chemical forms or species of these heavy metals since they control their bioavailability or mobility which ultimately control heavy metal soil-plant transfer [26, 27]. Poisonous metals may be absorbed by crops through several processes and finally, enter the food chain at high concentrations capable of causing a serious health risk to consumers.

Some metals, such as $\mathrm{Mn}, \mathrm{Cu}, \mathrm{Zn}, \mathrm{Mo}$, and $\mathrm{Ni}$, are essential or beneficial micronutrients for microorganisms, plants, and animals [28]. Their absence may cause deficiency diseases but at high concentrations, all have strong toxic effects and pose an environmental threat. Some heavy metals such as $\mathrm{Cd}$ and $\mathrm{Pb}$ have been known to have no known biological importance [29]. Their injuriousness can damage or reduce mental and central nervous function, lower energy levels, and damage to blood composition, lungs, kidneys, liver, and other vital organs. Long-term exposure may result in slowly progressing physical, muscular, and neurological degenerative processes that cause muscular and multiple dystrophies [17]. Therefore, the present study was carried out to assessing heavy metals concentration in the soil and crops are grown around dumpsites in Surakarta (TPA Putri Cempo dumpsites). Even if various studies have been carried out in the same study area, none of them studied the concentration of heavy metals in the soil and crops grown around this particular landfill. 2 sites will be selected from the dumpsite code-named TPA1 \& TPA2, Mojosongo dumpsite, and one control site at Central Java. It is expected that results obtained from the study will widen our knowledge of the environmental risks associated with solid waste dumps and crops grown around dumpsites.

\section{Materials And Methods Description of the Study Area}

Surakarta known colloquially as Solo is a city in Central Java, Indonesia. The $46 \mathrm{~km} 2$ (16.2 sq mi) city adjoins Karanganyar Regency and Boyolali Regency to the north, Karanganyar Regency and Sukoharjo Regency to the east and west, and Sukoharjo Regency to the south. On the eastern side of Solo lies Solo River (Bengawan Solo). Its built-up area, consisting of Surakarta Municipality and 59 districts spread over seven regencies, was home to $3,649,254$ inhabitants as of 2010 census.
Surakarta as a dense core city in Central Java, and its second city, spills considerably into neighboring regencies. Though a traffic study quotes the population as $1,158,000$ as of 2008 , this reflects only the very core, as the city affects entire neighboring regencies by significantly driving up overall population densities in Sukoharjo Regency and Klaten Regency over the already dense countryside. Furthermore, the government of Indonesia officially defines a broader region as Surakarta's extended metropolitan zone, with the acronym Subosukawonosraten as the city and 6 surrounding regencies, which reflects a broader planning region, though not a core metropolitan area as some of its regencies are not particularly suburbanized. Both the metropolitan area and extended areas border Yogyakarta's metropolitan area, while only the extended metropolitan area borders Kedungsapur or Greater Semarang.

Trash Disposal Site (TPA) Putri Cempo covers 17 hectares of land, was designed with a capacity to accommodate trash for only up to 20 years but the disposal site has operated for almost 30 years. Mojosongo dumpsite is also another landfill dumpsite in Surakarta.

\section{Sample collection and preparation}

Six sampling spots at a different distance of 50 $\mathrm{m}$ from each other were mapped out for soil sample collection within the sampling sites, using a clean stainless steel shovel from $0-15 \mathrm{~cm}$ depth. A soil sample to serve as control was also collected. The collected dried soil samples were thoroughly mixed in a clean plastic bucket to obtain a representative sample, crushed, air-dried, and sieved with $2 \mathrm{~mm}$ mesh before stored in labeled polythene bags prior to analysis.

The crop from the sample site was uprooted washed with distilled water to eliminate airborne pollutants, sliced and dried to eliminate excess moisture. These crop samples were weighed and ovendried at $60^{\circ} \mathrm{C}$ to constant weight. Each oven-dried sample was ground in a mortar until it could pass through a $0.18 \mathrm{~mm}$ sieve. The samples were then stored in a clean, dry, stoppered glass container before analysis.

\section{Determination of Soil $\mathbf{P}^{\mathrm{H}}$}

The $\mathrm{pH}$ of the samples was recorded using Corning $\mathrm{pH}$ meter, by introducing the meter probe into the prepared sample solution.

\section{Organic Matter Determination}

The soil samples were ground to pass through a $0.5 \mathrm{~mm}$ sieve after which they were weighed in duplicate and transferred to $250 \mathrm{~mL}$ Erlenmeyer flasks. Exactly $10 \mathrm{~mL}$ of $1 \mathrm{M}$ potassium dichromate was pipette into each flask and swirled gently to disperse the soil followed by the addition of $20 \mathrm{~mL}$ of concentrated, tetraoxosulphate (IV) acid. The flask was swirled gently 
until soil and reagents were thoroughly mixed. The mixture was then allowed to stand for 30 minutes on a glass plate to allow for the oxidation of potassium dichromate to chromic acid. Distilled water $(100 \mathrm{~mL})$ was added to 34 drops of ferroin indicator, after which the mixture was titrated with $0.5 \mathrm{M}$ ferrous sulfate solution. A blank titration was similarly carried. The percentage organic carbon is given by the following equation:

\section{$\frac{\left(\mathrm{M}_{1} \mathrm{e}_{1} \mathrm{~K}_{2} \mathrm{Cr}_{2} \mathrm{O}_{7}-\mathrm{M}_{2} \mathrm{e}_{2} \mathrm{FeSO}_{4}\right) \times 0.0031 \times 100 \times \mathrm{F}}{\text { Mass }(\mathrm{g}) \text { of air-dried soil }} \cdots \cdots \cdots \cdots \cdots \cdots \cdot \mathrm{e} 1$}

Where: $\mathrm{F}=$ correction factor (1.33), $\mathrm{M}_{1}=$ mole of $\mathrm{K}_{2} \mathrm{Cr}_{2} \mathrm{O}_{7}, \mathrm{e}_{1}=$ volume of $\mathrm{K}_{2} \mathrm{Cr}_{2} \mathrm{O}_{7}, \mathrm{M}_{2}=$ mole of $\mathrm{FeSO}_{4}$, and $\mathrm{e}_{2}=$ volume of $\mathrm{FeSO}_{4}$.

\section{Determination of heavy metals}

Triplicate samples of $1.0 \mathrm{~g}$ of the sieved soil samples were digested with $25 \mathrm{~mL}$ of a mixture of hydrochloric acid $(\mathrm{HCl})$ and trioxonitrate (v) acid $\left(\mathrm{HNO}_{3}\right)$ in the ratio of three to one parts by volume respectively at $120^{\circ} \mathrm{C}$ on a water bath in a fume cupboard. The solution was heated to dryness and the residue was dissolved in $5 \mathrm{~mL}$ of $2.0 \mathrm{M} \mathrm{HClO}$. On cooling, the digest was filtered into a $50.0 \mathrm{ml}$ volumetric flask and made up to the mark with distilled water. Exactly $8 \mathrm{ml}$ of $\mathrm{HNO}_{3}$ were added to $0.5 \mathrm{~g}$ of samples and left to stand overnight. The solution was then heated for one hour at $120^{\circ} \mathrm{C}$ on the hot plate with several additions of $4 \mathrm{~mL} \mathrm{H}_{2} \mathrm{O}_{2}$. After heating cooled and filtered. The filtrate was made up to $50 \mathrm{ml}$ of distilled water. Blanks were prepared to check for background contamination by the reagents used.

\section{Metal Analysis}

The digest samples were analyzed for heavy metals ( $\mathrm{Mn}, \mathrm{Cr}, \mathrm{Cd}, \mathrm{Pb}$, and $\mathrm{Fe}$ ) using atomic absorption spectrophotometer (AAS Buck Scientific model 210). The instrument setting and operational conditions were done in accordance with the manufacturers' specifications.

\section{Statistical AnAlysis}

Mean concentrations of heavy metals in soil and crops were analyzed using Statistical Program for Social Sciences (SPSS) and Microsoft Excel Software.

\section{Results AND Discussion}

Table 1 shows the result of the $\mathrm{pH}$ value and organic matter content of the soil samples. The TPA1, TPA2, Mojosongo Dumpsite (MOJ), and the CONTROL site represented by TPA1, TPA2, MOJ and CONTROL respectively.

Table-1: Physiochemical property of the soil samples

\begin{tabular}{|l|l|l|l|l|}
\hline Sites & TPA1 & TPA2 & MOJ & Control \\
\hline $\mathrm{pH}$ & $10.20 \pm 0.01$ & $9.10 \pm 0.02$ & $9.72 \pm 0.12$ & $8.30 \pm 0.00$ \\
\hline \%Organic matter & $2.88 \pm 0.04$ & $3.29 \pm 0.13$ & $3.01 \pm 0.02$ & $0.2 \pm 0.00$ \\
\hline
\end{tabular}

From the above $\mathrm{pH}$ ranges, it shows that all the soils are alkaline which is in agreement with research reported by Huang et al. [30] on abandoned open dumpsite in eastern China. The mean $\mathrm{pH}$ values of the studied soils were greater than the value obtained on the control site. This higher value of the $\mathrm{pH}$ may be a result of mineral build-up by wastes on the dumpsite. The higher $\mathrm{pH}$ dumpsite against its control site is similar to the $\mathrm{pH}$ reported by Prechthai et al. [19] on a dumpsite, Banten Province. It has been reported that most soils within the $\mathrm{pH}$ range of 6.0-9.0 have metals that are not always in the free form, hence not likely to be bioavailable. The $\mathrm{pH}$ of all the soil samples investigated is within this range therefore, the metals investigated in this study possibly may not be bioavailable to the plant until when favorable conditions like acidic precipitation prevailed on the soil. $\mathrm{pH}$ plays a significant role in solute concentration and sorption and desorption of contaminants in soil [31].

The soil organic matter enhances the usefulness of soils for agricultural purposes. It supplies essential nutrients and functions as a source of food to microbes and thereby helps to enhance and control their activities [22]. The percentage of organic matter of all the sites was found to be higher than the percentage of organic matter of the control site. The higher percentage of the organic matter recorded may have resulted from the decomposition and composting processes of the organic wastes such as food wastes etc. as a result of their location close to market and school. The result from this research is lower than the 7.62 to $8.60 \%$ organic matter reported by Prechthai et al. [19] on a dumpsite, Banten Province. This shows a positive indication that the soil is fertile and likely to support the healthy growth of crops which may attract the attention of farmers to the locations. Huang et al. [30] reported that the organic matter content of soil contributes to the increase in the availability of mineral elements, nutrition to living organisms and acts as a buffer aqueous solution to maintain a neutral $\mathrm{pH}$.

The concentration of heavy metals in soil samples is presented in Table 2. The results above obtained showed that soils from the study sites have higher metal concentrations than their corresponding 
metals level at the control site. This is in agreement with the results obtained from similar studies by Jarup [23] on a dumpsite in Central Java and it could be attributed to the availability of metal-containing wastes at dumpsites which have eventually leached into the underlying soils. The metal concentrations of the selected heavy metals ( $\mathrm{Mn}, \mathrm{Cd}, \mathrm{Cr}, \mathrm{Pb}$, and $\mathrm{Fe}$ ) were compared with World Health Organization (WHO) standards, and all were found to be lower than the WHO maximum permissible limit.

Table-2: Heavy metal concentration in soil samples

\begin{tabular}{|l|l|l|l|l|l|}
\hline Sites & TPA1 $(\mathbf{m g} / \mathbf{K g})$ & TPA2 $(\mathbf{m g} / \mathbf{K g})$ & MOJ $(\mathbf{m g} / \mathbf{K g})$ & Control $(\mathbf{m g} / \mathbf{K g})$ & WHO MPL $(\mathbf{m g} / \mathbf{K g})$ \\
\hline $\mathrm{Mn}$ & $610 \pm 9.73$ & $283.56 \pm 1.17$ & $341.36 \pm 3.46$ & $210.91 \pm 0.65$ & 2000 \\
\hline $\mathrm{Cr}$ & $33.96 \pm 0.88$ & $48.03 \pm 0.78$ & $37.56 \pm 2.48$ & $23.25 \pm 0.22$ & 100 \\
\hline $\mathrm{Cd}$ & $1.09 \pm 0.07$ & $0.74 \pm 0.04$ & $0.94 \pm 0.03$ & $0.14 \pm 0.00$ & 3 \\
\hline $\mathrm{Pb}$ & $31.05 \pm 0.54$ & $9.98 \pm 1.33$ & $14.55 \pm 1.33$ & $0.6 \pm 0.00$ & 100 \\
\hline $\mathrm{Fe}$ & $9112.33 \pm 49.834$ & $8261.70 \pm 138.71$ & $8403 \pm 32.9$ & $5251.92 \pm 51.60$ & 50000 \\
\hline
\end{tabular}

Manganese is found naturally in most soil as it is one of the most essential minerals for life [32]. The result from this study is similar to the result from Alam et al. [33] on the distribution and enrichment of heavy metals in soils from waste dumpsites in Chittagong, Bangladesh. All the concentration of manganese values was found to be lower than the World Health Organization standard for manganese in the soil. The mean concentration of chromium in studied soil ranges from $33.08 \mathrm{mg} / \mathrm{kg}$ to $34.84 \mathrm{mg} / \mathrm{kg}$ higher than the mean value of $23.47 \mathrm{mg} / \mathrm{Kg}$ at the control site. This implies that the high concentrations at the dumpsite are the result of the dumping of Cr-containing waste. Sources of chromium might be due to wastes from household chemicals and cleaners, diesel engines utilizing anticorrosive agents, rubber, candles, and matches, etc. Anthropogenic input of $\mathrm{Cr}$ comes from solid wastes, where approximately $30 \%$ of $\mathrm{Cr}$ originates from plastics, packaging materials, and lead chromium batteries [19]. The values of $\mathrm{Cr}$ obtained in this study were lower than the $900-2000 \mathrm{mg} / \mathrm{kg}$ reported by Jarup [23] in a dumpsite in Central Java. The highest percentage of cadmium, lead, and iron was noted in TPA1. Even though it was higher, still yet lower than the maximum permissible limit. Among all the metal studied in this research, the concentrations of Fe has the highest values throughout the sites.
Table 3 shows the mean concentrations of metals in the crops grown around the dumpsites. Throughout the sites, only manganese and iron were absorbed by the plants at a very significant concentration. The factors affecting the amount of metal absorbed by a plant are (i) the concentration and speciation of the metal in the soil solution (ii) the movement of the metal from the bulk soil to the root surface (iii) the transport of the metal form the root surface into the root, and (iv) its translocation from the root to the shoot [31].

One or more of these controlling factors may have been responsible for the wide variation in the concentration and pattern of uptake observed for the various metals in the crops. The measure of the concentration of these metals in the crops reflected their corresponding concentrations in the soil. Thus agreed with what some authors have noted, that plant uptake of metal from the soil is largely determined by the concentration of the metal in the soil matrix [23]. The manganese and iron that have a significant concentration were more than the control site which means there is a likelihood of anthropogenic input on the crop from the dumpsite. They were below the maximum permissible level which implies that they are safe for consumption although continuous build-up could make the crops unsafe for consumption.

Table-3: Heavy metal concentration in crops

\begin{tabular}{|l|l|l|l|l|l|}
\hline Metals & TPA1 $(\mathbf{m g} / \mathbf{K g})$ & TPA2 $(\mathbf{m g} / \mathbf{K g})$ & MOJ $(\mathbf{m g} / \mathbf{K g})$ & CONTROL $(\mathbf{m g} / \mathbf{K g})$ & WHO MPL (mg/Kg) \\
\hline $\mathrm{Mn}$ & $51.00 \pm 0.78$ & $88.05 \pm 1.35$ & $66.32 \pm 2.24$ & $36.72 \pm 2.50$ & 500 \\
\hline $\mathrm{Fe}$ & $180.37 \pm 5.0$ & $329.92 \pm 4.57$ & $201.11 \pm 1.17$ & $149.98 \pm 2.37$ & 425 \\
\hline $\mathrm{Cr}$ & ND & ND & ND & ND & 2.3 \\
\hline $\mathrm{Cd}$ & ND & ND & ND & 0.10 \\
\hline $\mathrm{Pb}$ & ND & ND & ND & 0.30 \\
\hline
\end{tabular}

\section{CONCLUSION}

This research has shown that there is heavy metal pollution on dumpsites soil which is the resulting effect of heavy metal-containing wastes that are improperly disposed of there. Buildups of heavy metal on these dumpsites have leached to the nearest place of uptake by crops around them. Although, the soil and crops studied were found to be safe for now but there are concerns for the gradual and continuous buildup which has started and indicated in the obvious difference of the dumpsites and control site metal concentration. This study shows that continuous cultivation of consumable crops in or around dumpsites is highly risky to humans and also it is necessary to take 
measures both to stop cultivating crops and to conduct a public talk on the risks associated with dumpsite.

\section{ACKNOWLEDGEMENTS}

This research did not receive any funding or financial supports from any public or private body.

\section{REFERENCES}

1. Hussain, M., Haider, S., Abbas, Y., Khan, Q., Hussain, B., Hussain, S. W., ... \& Ali, A. (2016). A Study of Source Specific Quantification, Composition and Disposal Methods of Municipal Solid Waste at Konodas Gilgit City, Pakistan. J. Biodivers. Environ. Sci., 8(5), 2016222220166663.

2. ZUL, A., LA, O. A., \& MUHAMMAd, N. (2017). Heavy metal content of cocoa plantation soil in East Kolaka, Indonesia. Oriental Journal of Chemistry, 33(3), 1164-1170.

3. Rachim, D.A. (2007). Fundamentals Genesis Land. Department of Soil Science and Land Resources Fakulstas Agriculture, 2007, Bogor.

4. Ugurlu, A. (2004). Leaching characteristics of fly ash. Environ Geol, 46:890-895

5. Srigirisetty, S., Jayasri, T., \& Netaji, C. (2017). Open dumping of municipal solid waste-Impact on groundwater and soil. Tech. Res. Organ. India, 4(6), 26-33.

6. Singh, S., \& Kumar, M. (2006). Heavy metal load of soil, water and vegetables in peri-urban Delhi. Environmental Monitoring and Assessment, 120(1), 79-91.

7. Hoornweg, D., \& Bhada-Tata, P. (2012). What a waste: a global review of solid waste management.

8. Ozcan, H. K., Guvenc, S. Y., Guvenc, L., \& Demir, G. (2016). Municipal solid waste characterization according to different income levels: A case study. Sustainability, 8(10), 1044.

9. Tariq, S. (2001). Environmental geochemistry of surface and sub surface water and soil in Peshawar basin of NWFP Pakistan. Unpublished PhD thesis, University of Peshawar.

10. Ramachandra, T. V., \& Bachamanda, S. (2007). Environmental audit of municipal solid waste management. International Journal of Environmental Technology and Management, 7(34), 369-391.

11. Rasmussen, C., Matsuyama, N., Dahlgren, R. A., Southard, R. J., \& Brauer, N. (2007). Soil genesis and mineral transformation across an environmental gradient on andesitic lahar. Soil Science Society of America Journal, 71(1), 225237.

12. Postma, D., Larsen, F., Hue, N. T. M., Duc, M. T., Viet, P. H., Nhan, P. Q., \& Jessen, S. (2007). Arsenic in groundwater of the Red River floodplain, Vietnam: controlling geochemical processes and reactive transport modeling. Geochimica

et

Acta, 71(21), 5054-5071.

13. Sridevi, V., Modi, M., Ch, M. V. V., Lakshmi, A., \& Kesavarao, L. (2012). A review on integrated solid waste management.

14. Misra, A., Tirpathi, B.D. (2008). Heavy metal contamination of soil, and bioaccumulation in vegetables with treated wastewater in the tropical city of Varanasi, India. Toxicol Environ Chem, 90:861-871

15. Yilmax, A.B. (2005). Comparison of heavy metals of Grey mullet (M. Cephalus L.) and Sea bream (S. Aurata L.) caught in Iskenderun Bay (Turkey). Turk. J. Vet. Anim. Sci, 29, 257.

16. Chang, H. H. (1992). Fluvial processes in river engineering.

17. Phothisansakul, A., \& Runguphan, T. (2017). Remediation of Domestic Wastewater Runoff Using Vermi-biofiltration. Int. J. Environ. Bioremediation Biodegrad, 5(2), 60-64.

18. Alloway, B., \& Ayres, D. C. (1997). Chemical principles of environmental pollution. CRC press.

19. Prechthai, T., Parkpian, P., \& Visvanathan, C. (2008). Assessment of heavy metal contamination and its mobilization from municipal solid waste open dumping site. Journal of Hazardous Materials, 156(1-3), 86-94.

20. Tankari Dan-Badjo, A., Guero, Y., Dan Lamso, N., Baragé, M., Balla, A., Sterckeman, T., ... \& Feidt, C. (2013). Évaluation des niveaux de contamination en elements traces métalliques de laitue et de chou cultivés dans la vallée de Gounti Yéna à Niamey, Niger. Journal of Applied Biosciences (67), 5326-5335.(2013).

21. Cataldo, D. A., \& Wildung, R. E. (1978). Soil and plant factors influencing the accumulation of heavy metals by plants. Environmental Health Perspectives, 27, 149-159.

22. Hang, X., Wang, H., Zhou, J., Ma, C., Du, C., \& Chen, X. (2009). Risk assessment of potentially toxic element pollution in soils and rice (Oryza sativa) in a typical area of the Yangtze River Delta. Environmental pollution, 157(8-9), 25422549.

23. Jarup, L. (2003). Hazards of heavy metals contamination. British Medical Bulletin, 68:167182.

24. Nyangababo, J. T., \& Ichikuni, M. (1986). The use of cedar bark in the study of heavy metal contamination in the Nagatsuta area, Japan. Environmental Pollution Series B, Chemical and Physical, 11(3), 211-229.

25. Ellis, D. R., \& Salt, D. E. (2003). Plants, selenium and human health. Current opinion in plant biology, 6(3), 273-279.

26. Kabata-Pendias, A. (2004). Soil-plant transfer of trace elements - an environmental issue. Geoderma, 122(2-4), 143-149.

27. Gupta, A. K., \& Sinha, S. (2006). Chemical fractionation and heavy metal accumulation in the 
plant of Sesamum indicum (L.) var. T55 grown on soil amended with tannery sludge: Selection of single extractants. Chemosphere, 64(1), 161-173.

28. Yasin, H., \& Usman, M. (2017). Site investigation of open dumping site of Municipal Solid Waste in Faisalabad.

29. Nascimento, V. F., Sobral, A. C., Andrade, P. R., Yesiller, N., \& Ometto, J. P. H. B. (2017). Natural disaster risk in municipal solid waste disposal sites using GIS: a case study in São Paulo state, Brazil. Journal of Water Resource and Protection, 9(11), 1213.

30. Huang, Y., Li, Y., Yang, J., Xu, M., Sun, B., Gao, F., \& Wang, N. (2015). Harmful chemicals in soil and risk assessment of an abandoned open dumpsite in Eastern China. Journal of Chemistry, 2015.
31. Singh, J., Upadhyay, S. K., Pathak, R. K., \& Gupta, V. (2011). Accumulation of heavy metals in soil and paddy crop (Oryza sativa), irrigated with water of Ramgarh Lake, Gorakhpur, UP, India. Toxicological \& Environmental Chemistry, 93(3), 462-473.

32. Adeniyi, A. A., Yusuf, K. A., \& Okedeyi, O. O. (2008). Assessment of the exposure of two fish species to metals pollution in the Ogun river catchments, Ketu, Lagos, Nigeria. Environmental Monitoring and Assessment, 137(1), 451-458.

33. Alam, M. T., Manoharan, M. P., Haque, M. A., Muratore, C., \& Voevodin, A. (2012). Influence of strain on thermal conductivity of silicon nitride thin films. Journal of Micromechanics and Microengineering, 22(4), 045001.

Cite This Article: Philomene Nyiramigisha et al (2021). Assessment of Heavy Metals Concentration in the Soil and Crops Grown around Dumpsites. East African Scholars J Agri Life Sci, 4(4), 82-88. 